American Journal of Pharmaceutical Education 2019; 83 (1) Article 6976.

\title{
REVIEW
}

\section{Identifying Components of Success Within Health Sciences-Focused Mentoring Programs Through a Review of the Literature}

\author{
MaryPeace McRae, PharmD, PhD, Kristin M. Zimmerman, PharmD \\ School of Pharmacy, Virginia Commonwealth University, Richmond, Virginia \\ Submitted January 24, 2018; accepted April 22, 2018; published February 2019.
}

Objective. To identify programmatic components and structural features associated with success of mentoring programs within the health sciences.

Findings. Thirty-eight manuscripts representing 34 individual programs were reviewed. Of the institutions represented, $68 \%$ were public. Sixty-eight percent of programs included single disciplines only, with four focused in pharmacy, 13 in medicine, and six in nursing. Of the 34 individual programs, all programs reporting participant confidence and self-efficacy reported success in that domain. Eighteen programs reported outcomes related to scholarly activity that included publications or funding/ grantsmanship; 16 reported success. Eleven of 16 programs reporting promotion/tenure and/or faculty retention rates reported success. Program components associated with successful programs included frequent meetings (at least monthly) and delivering content within formal curricula. Content categories common within programs reporting success were content related to research, funding/grantsmanship and networking/collaboration. In addition, specific for the promotion/retention domain, content related to curriculum/teaching was commonly found within successful programs.

Summary. Although somewhat dependent on the program's specific goals, curriculum most commonly associated with success contained content on research, grantsmanship/funding, curriculum/ teaching, and networking/collaboration. Among many programs, the reporting lacked objective, standardized metrics and often included only generalized descriptions/categorization of course content. The incomplete and inconsistent reporting limited our ability to draw conclusions regarding individual topics important for each program component. Proper planning, execution, and assessment of faculty mentoring programs is critical to the identification of additional program characteristics for optimal faculty success.

Keywords: faculty mentoring, health sciences, faculty, program development, faculty development

\section{INTRODUCTION}

Faculty attrition is a significant concern within the health sciences. Poor attrition rates increase both direct and indirect costs to institutions. This includes cost of the lost opportunity, new faculty recruitment efforts, and the training of inexperienced faculty. Other intangible costs include loss of faculty continuity and faculty connectedness. ${ }^{1}$ In at least one study, $34 \%$ of medical faculty resigned within three years of hire. ${ }^{2}$ Of those faculty who remained active, an additional $48 \%$ reported they were considering leaving their positions within the next five years. ${ }^{2}$ In another survey of faculty across 26 U.S. medical schools, $35 \%$ of faculty reported they had

Corresponding Author: MaryPeace McRae, Department of Pharmacotherapy and Outcomes Science, School of Pharmacy, Virginia Commonwealth University, 410 N. $12^{\text {th }}$ St., Richmond, VA 23298. Tel: 804-628-5076. E-mail: mpmcrae@vcu.edu seriously considered leaving their current position during the prior year. ${ }^{3}$ Faculty leave their positions for various reasons, including lack of professional development, inclusiveness, or institutional recognition and support. ${ }^{2}$ In one report, $34 \%$ of recent former faculty at a small, private research university cited lack of mentoring as a cause of their dissatisfaction. ${ }^{4}$

Lack of mentorship has been identified as an important barrier to career development and satisfaction within academia. ${ }^{2,5,6}$ In a qualitative study of 16 junior faculty members within academic medicine, $98 \%$ of participants identified lack of mentorship as a barrier to their career progression. ${ }^{6}$ Meanwhile, effective mentoring has been shown to result in positive career outcomes; studies have demonstrated that mentoring is related to enhanced career development, career progression, and enhanced research productivity. ${ }^{5,7,8}$ Mentoring is also associated with higher rates of promotion, ${ }^{9}$ with one study demonstrating that 


\section{American Journal of Pharmaceutical Education 2019; 83 (1) Article 6976.}

mentored academic clinicians were promoted more quickly, had higher retention rates and reported greater self-efficacy and career satisfaction. ${ }^{7}$ Other studies have also demonstrated enhanced career satisfaction, ${ }^{10,11}$ clarity of professional identity, and sense of competence in those who have been mentored. ${ }^{8}$

The concept of mentoring can be theorized in a variety of ways. The traditional view on mentoring is that in which there is a senior individual within the same organization assisting the junior person's personal and professional development. ${ }^{10}$ Within this model, the mentor provides both career and psychosocial assistance. ${ }^{8,11} \mathrm{~A}$ main assumption of this traditional dyad model is that success of the mentoring is related to the amount of mentoring time spent. ${ }^{10}$ More recently the concept of mentoring has begun to expand beyond the traditional dyad pair to include alternative forms of mentoring relationships, such as peer relationships, mentoring circles, e-mentoring, and personal discussion networks. With the expansion of different types of mentoring came the recognition that mentoring is more than just the single dyad model. This led to the proposal of mentoring as a developmental network, which includes a constellation of mentoring relationships and functions. In order for the network to be maximally effective, it must also be broad and diverse; including contacts within and outside of the organization, members at different stages of their careers and members of different demographic groups. Having various members of the network allows the mentee to enlist help from others when one particular mentor's abilities are limited at a critical point in the mentee's career. ${ }^{12}$

Despite the evidence that mentoring is important, formal programs within the health sciences are not widespread or vary greatly in content and structure. In a survey of 78 U.S. schools and colleges of pharmacy in 2000 , only $18 \%$ of respondents reported that their college or school had a formal faculty mentoring program, and 53\% reported that their institution had only informal mentoring. ${ }^{13}$ Among institutions that have faculty mentoring programs, the quality and type of mentoring can vary greatly. The lack of faculty mentoring or use of unstructured programs may have an adverse impact on faculty success and retention. In addition to the wide variability in program design, there are also inconsistencies in outcome assessment. In a survey of faculty mentoring programs within pharmacy schools and colleges, $58 \%$ of the institutions with some form of faculty mentoring reported they had no easy way to measure the outcomes of their program. ${ }^{13}$ Without clear and effective metrics, programs may struggle to capture outcomes and convey their value to university administrators and participants.

There are very few systematic evaluations of faculty mentoring programs and even fewer evaluations specifically focused on health sciences faculty. In this article, we systematically reviewed and evaluated published papers that report the development and/or implementation of health sciences faculty mentoring programs. The primary goal of this review was to identify specific aspects of program structure and program components associated with successful mentoring programs.

\section{METHODS}

A systematic review of the Education Resources Information Center (ERIC), Education Research Complete (ERC), and PubMed databases for publications related to faculty mentoring programs in higher education was conducted. The search string included versions of the terms "mentor," "program," and "faculty" as well as excluded versions of "fellow" or "student." Records were limited to higher education within the ERIC database and results from all searches were screened by two independent reviewers. Titles and abstracts considered irrelevant were discarded. Full-text articles were assessed for eligibility by both reviewers. During this review, references were scanned for omissions from original search results. To be included, studies must have been written in English, conducted at a U.S. institution for higher learning, sufficiently described the development or implementation of a multifaceted mentoring program that included on-campus, health sciences faculty, and had a live mentoring component. Studies focusing solely on mentor or administrator training, or those conducted at community colleges or with faculty teaching only in online degree programs were excluded.

To promote consistency in data extraction from mentoring program publications, a data extraction form was developed. The initial version of the data extraction form was used independently by both reviewers on three test publications. The reviewers then met to compare data extracted and to discuss their experience with using the extraction sheet. As a result, small modifications were made and this final form was used for all subsequent data extraction from the articles by the two independent reviewers. Collected data included a description of the institution, data regarding the program development or implementation, the catalyst for the program development, program objectives, mentee and mentor characteristics, program infrastructure and structure, and details regarding the outcome assessment. Data extraction was the shared responsibility of both authors, and all data were entered into the database after consensus from both authors.

Published mentoring programs in the final sample were analyzed qualitatively. For studies explicitly reporting their program goals, these goals were categorized into three main themes: professional development (eg, career development, culture change, individual goal setting); 


\section{American Journal of Pharmaceutical Education 2019; 83 (1) Article 6976.}

research and scholarly activity (eg, publications, grants, called "scholarly activity" throughout this manuscript); and promotion, tenure and faculty retention (termed "promotion/retention" throughout this manuscript). Similarly, for studies explicitly reporting program outcomes, these outcomes were categorized into three main themes, two of which mirror the goal categories: scholarly activity and promotion/retention. The third main outcome theme was "confidence and self-efficacy." For studies reporting outcomes for these themes, an assessment of success was conducted. As success was reported differently among studies, outcomes were evaluated by two independent reviewers and entered into the database by consensus. Success was defined and coded as an increase or improvement from baseline, relative increase over a comparator group (eg, a control group, if applicable), programs that authors self-identified as successful or presented outcomes data that reviewers identified as successful. For two of the outcome themes, scholarly activity and promotion/retention, common content areas and program qualities were identified. These components were queried against programs determined to be "successful" or "success not determined" for each theme. Components included content areas related to research (including design and writing skills), funding/grantsmanship, curriculum and teaching, networking/collaboration, workload/time management, and promotion/tenure. Program qualities included frequency of meetings (categorized as least monthly or less frequently), duration of the mentoring program and length of evaluation period. A subset analysis of programs with stated goals of either scholarly activity or promotion/ retention tracked the content delivered and outcomes assessed relative to the stated goal.

\section{RESULTS}

ERIC, ERC and PubMed databases were searched and 846 records were retrieved. An additional 45 papers were retrieved from prior searches and reference reviews. After removal of duplicates, 479 records remained. During the screening process, 342 records were deemed irrelevant based on title and/or abstract review. There were 137 full articles assessed for eligibility, of which, 38 individual published papers remained in the final sample. Fiftytwo percent of the articles were excluded because of a lack of program description such as its design, structure, or components. Another common reason articles were excluded was because the programs did not include health sciences faculty.

Of the 38 studies in the final sample, there were four papers describing one individual mentoring program ${ }^{14-17}$ and two papers describing an additional single mentoring program. ${ }^{18,19}$ This yielded a representation of 34 total programs among the 38 publications. Both public $(68 \%$, $\mathrm{n}=23)$ and private $(32 \%, \mathrm{n}=11)$ institutions were represented. The specific composition of health science disciplines varied across studies; 23 programs included single disciplines only (68\%) and 11 mentoring programs included multiple schools/disciplines (32\%), with two of those programs being open to the entire institution. ${ }^{20,21}$ Of those focusing on single schools or disciplines, four programs focused on pharmacy, ${ }^{22-25} 13$ on medicine, ${ }^{14,19,26-36}$ and six on nursing. ${ }^{37-42}$

In most programs, mentees were characterized as early career faculty, whereas other programs accepted mentees of all rank. Mentors were typically, but not always, senior faculty. Twenty-three of the 34 individual programs reviewed assigned traditional mentor-mentee matches as part of their program (Table 1). ${ }^{*}$ In the other programs, mentoring occurred through peer mentoring or a mixed peer mentoring/dyad model. Other program components including mentor and mentee characteristics are listed in Table 1.

Of the studies reviewed, program goals were of one or more of the following themes: professional development (19 studies), ${ }^{* *}$ enhancing scholarly activity (15 studies), ${ }^{* * *}$ and improving faculty promotion/retention (14 studies). ${ }^{* * * *}$ Five of the 34 programs (15\%) reviewed and reported here did not describe specific goals for their programs. ${ }^{16,20,30,52,53}$

Content areas covered within all of the faculty mentoring programs consistently included research (27 programs), curriculum/teaching (19 programs), funding/ grantsmanship (18 programs), promotion/tenure (17 programs), networking/collaboration (16 programs), and communication/feedback (15 programs). Most program content was imbedded formally into the curriculum in the form of workshops, conferences, and seminars as well as through writing groups, individual consultations, and facilitated peer mentoring.

Most programs reporting on the outcomes of their faculty development programs used data sources such as survey data, ${ }^{* * * *}$ activity records, ${ }^{22,26,27,50}$ interviews, ${ }^{25-27,37,47,50}$ and focus groups." "Spontaneous reporting,",22 reflection sheets, ${ }^{31,50}$ performance reviews, ${ }^{16}$ and pre- and postcompetency assessments were also assessed. ${ }^{37,50}$

Commonly assessed outcomes included mentee satisfaction with the program, mentee retention within the development program, ${ }^{18,19,24-27,31,33,36}$ and overall perception

\footnotetext{
*14-20,22,23,25-27,30,33-35,39-49

**14,15,18,21-24,26,31,32,34-36,40-44

***19,25,28,29,33,36-39,43,45,47,49-51

****17,18,23,25,27-29,32-34,36,38,43,46

*****14-16,18-30,32-37,40-45,49,50,52,53

\#23,24,26,31,35,37,49,53
} 
American Journal of Pharmaceutical Education 2019; 83 (1) Article 6976.

Table 1. Mentoring Program Characteristics and Components ${ }^{\mathrm{a}}$

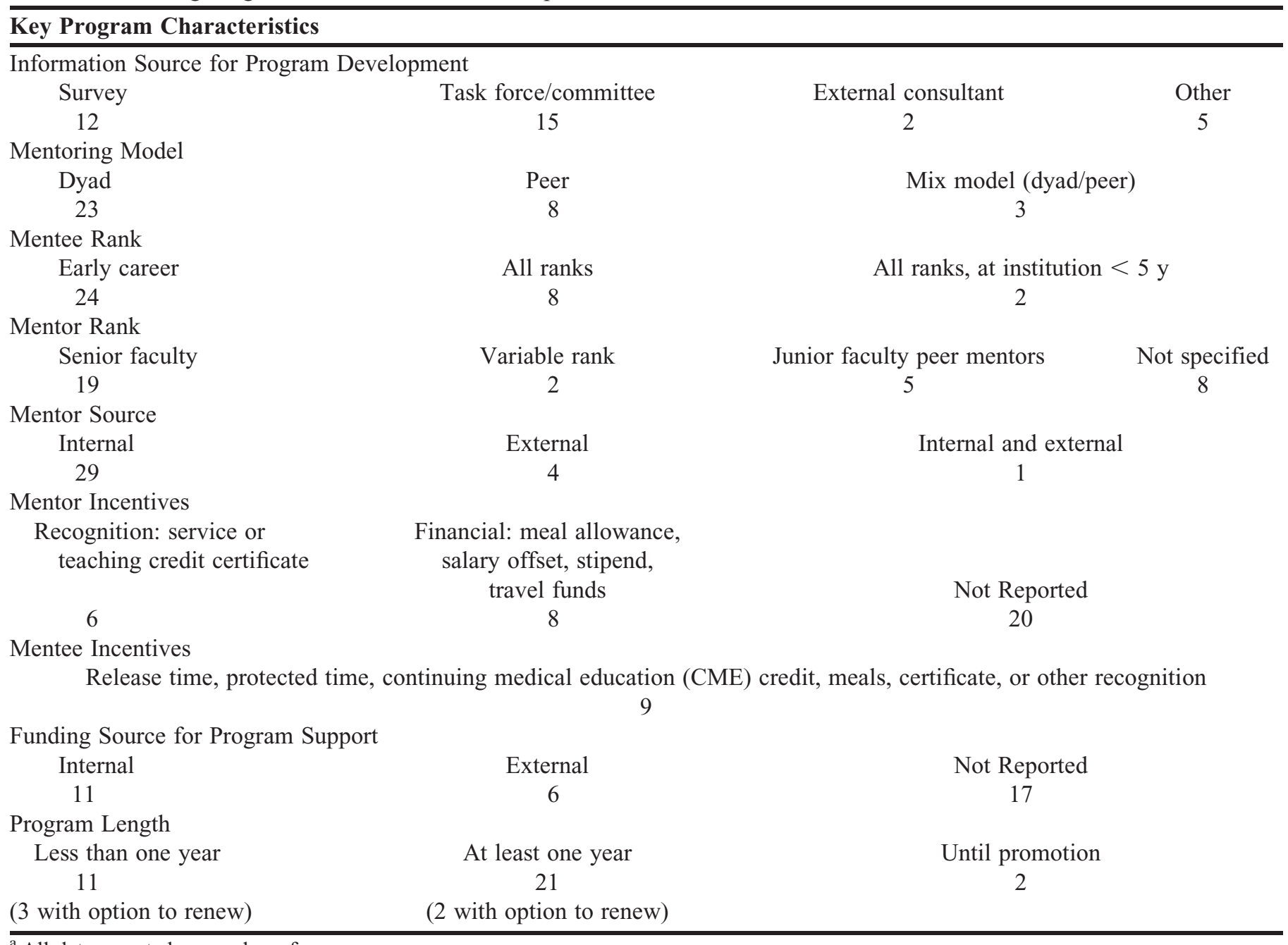

${ }^{\mathrm{a}}$ All data reported as number of programs

of the program (Appendix 1). ${ }^{\# \#}$ Furthermore, outcomes related to scholarly productivity, ${ }^{\# \# \#}$ promotion and/or retention, ${ }^{\# \# \# ~ a n d ~ s e l f-e f f i c a c y ~ a n d / o r ~ c o n f i d e n c e ~ w e r e ~ a l s o ~}$ measured (Appendix 2).

Of studies assessing program satisfaction, all reported that participants were "somewhat" to "highly satisfied" with the program."\#\#\# Identified strengths of programs included: one-on-one assignments, ${ }^{22,44}$ use of prioritized goals, ${ }^{20}$ and enhanced social connection. ${ }^{36}$ The most frequently identified barrier was the difficulty finding time to meet. ${ }^{20-22,32,41,43}$ Self-identified areas for improvement included more frequent meetings, ${ }^{23,41,50}$ more guidance or training for mentors, ${ }^{20,37,44}$ and more structured, formal events. ${ }^{43}$ Additional information can be found in Appendix 1.

\footnotetext{
\#\#23-26,28,31,40-42,44,50,54

\#\#\#16,22,23,28,29,31-33,36-39,45,47,49,51-53

\#\#\#\#15-17,20,22,23,26-29,31-34,37,40,44,53

\#\#\#\#18-21,23-28,30-34,39,40,42-44,47,50,52
}

The number of programs reporting improvements in the outcome category of self-efficacy and self-confidence is listed in Table 2. Notable commonalities in menteereported improvement in confidence ratings included gaining a better understanding of promotion and advancement ${ }^{14,18,27,44,50,52}$ and a better understanding of department or university roles/responsibilities and processes. ${ }^{14,15,34}$ Other outcomes within the self-efficacy/self-confidence domain included enhanced knowledge of the research funding process, ${ }^{18,50}$ improved writing skills, ${ }^{28,33}$ and enriched worklife balance. ${ }^{27,50}$ Other findings are presented in Appendix 1.

The number of programs reporting improvements/ success in the outcome category of scholarly activity is listed in Table 2. Success for scholarly activity (grants or manuscripts/publications) was classified in one or more ways: an increase from baseline or comparator group (10 studies), self-reported improvement (six studies), ${ }^{28,31,37-39,51}$ or by determination by the study team (two studies). ${ }^{29,32}$ Of

$\wedge 11,17,18,28,31,33,36,43,44,48$ 


\section{American Journal of Pharmaceutical Education 2019; 83 (1) Article 6976.}

Table 2. Success Determination for the Main Outcome Themes

\begin{tabular}{|c|c|c|}
\hline $\begin{array}{l}\text { Outcome Theme (Number } \\
\text { of Programs Reporting Outcomes) }\end{array}$ & $\begin{array}{c}\text { Number of Programs Reporting } \\
\text { Improvements/Success }\end{array}$ & $\begin{array}{l}\text { Number of Programs for Which } \\
\text { Success Could Not be Determined }\end{array}$ \\
\hline Self-Efficacy/Self-Confidence $(n=11)$ & $11^{\mathrm{a}}$ & 0 \\
\hline $\begin{array}{l}\text { Promotion/Retention }(n=16) \text { with } \\
\text { promotion/tenure }(n=9) \text {, faculty } \\
\text { retention rates }(n=11)\end{array}$ & $11^{\mathrm{d}}$ & $5^{\mathrm{e}}$ \\
\hline $\begin{array}{l}\text { a Programs reporting improvements/success } \\
\text { b Programs reporting improvements/success } \\
\text { c Programs reporting scholarly activity outco } \\
{ }^{d} \text { Programs reporting improvements/success } \\
\text { e Programs reporting promotion/retention ou }\end{array}$ & $\begin{array}{l}\text { fficacy/self-confidence. }{ }^{14,15,18,19,26-28,33-} \\
\text { arly activity. }{ }^{16,22,23,28,29,31-33,36-38,44,46,48} \\
\text { which success could not be determined. } \\
\text { otion/retention. }{ }^{15-17,20,26-29,32,33,36,45,53}\end{array}$ & \\
\hline
\end{tabular}

the two studies determined by the research team to demonstrate success, one study reported 8 of 16 participants receiving NIH career development ("K") awards and the other study reported that 10 of 12 participants received 37 grants, totaling \$12.6 million from extramural sources. ${ }^{29,32}$

The number of programs reporting improvements/ success in the outcome category of promotion/retention is listed in Table 2. Of the successful programs, five reported an improvement relative to either baseline or a comparator group, ${ }^{15-17,26,27,33,53}$ and six presented data the research team determined was demonstrable of success. $^{20,22,28,29,32,37}$ Of the six programs that were determined by the research team to be successful, three reported $100 \%$ success rate for program participants that applied for promotion and one study reported 11 of 12 participants achieved promotion during the study period. ${ }^{20,28,29,37}$ One program reported approximately half of their participants were promoted within a short threeyear time frame. ${ }^{22}$ In another program in which all the participants were very early career (either those just making the transition from residency or post-doctoral training to faculty positions or those within their first two years of their faculty appointment), 14 of 16 participants were retained in traditional faculty positions (Appendix 2). ${ }^{32}$

\section{Themes Among Successful Programs}

Common themes within the programs demonstrating successful scholarly activity are included in Table 2 . Content regarding research, funding/grantsmanship, curriculum/ teaching, and networking/collaboration were common among programs that demonstrated successful scholarly activity. Networking content was demonstrated through the use of peer mentors, external mentors, staff mentors, writing groups, and service on community advisory boards, and almost all of these networks met at least monthly. ${ }^{\wedge}$ The meeting frequency of at

$\wedge 28,29,31,37,38,47,49,53$ least once monthly throughout the duration of the program was common to most (75\%) of the studies reporting scholarly success. ${ }^{M}$ Median program duration and median evaluation period for these studies are included in Table 3.

A comparison of the frequency of program content areas between programs reporting scholarly success and those for which success was not demonstrated was also made. Programs demonstrating scholarly success had higher rates of content related to funding/grantsmanship and were more likely to meet at least monthly. Research content was common among all programs reporting scholarly outcomes regardless of success determination and content related to networking and collaboration occurred in about half of the programs, regardless of the outcome related to scholarly activity (Table 3 ).

Content categories that were common within the 11 programs demonstrating success for promotion/retention included research, curriculum/teaching, funding/grantsmanship, and networking/collaboration. Additionally, successful programs had frequent meetings occurring at least once per month. The structure of these frequent meetings varied, ranging from formal curricular content to individual unstructured mentor-mentee meetings. Median program duration and median evaluation period for these studies are included in Table 4.

Compared to programs for which successful promotion/retention could not be determined, it was observed that successful programs more frequently had content related to both funding/grantsmanship and networking/collaboration. Content related to research/scholarship and curriculum/teaching were high, but not different among the two groups. Furthermore, the percentage of studies that met at least monthly was also high but not different between successful programs and those for which success could not be determined (Table 4). 
American Journal of Pharmaceutical Education 2019; 83 (1) Article 6976.

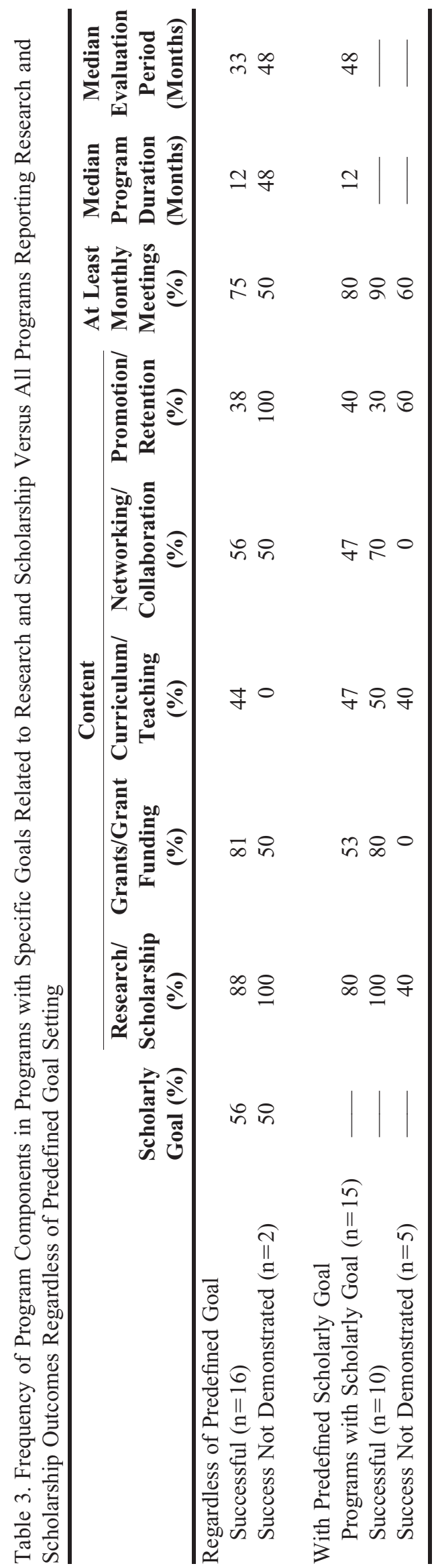

This subset analysis focused on evaluating how many programs aligned programmatic goals with their assessments for success. Overall, $73 \%$ of programs with a goal of scholarly activity subsequently conducted assessments for that goal (scholarly activity), whereas only $57 \%$ of programs with a goal of promotion/retention aligned their assessment accordingly. Of the programs that aligned goals to assessment that were also successful in enhancing scholarship $(n=10), 100 \%$ had content related to research/scholarship, $90 \%$ met at least monthly, $80 \%$ had program content related to funding/grants, and $70 \%$ had program content related to networking and collaboration (Table 3).

For aligned programs successful in enhancing promotion/retention $(n=6), 100 \%$ had content related to research/scholarship, $83 \%$ met at least monthly, $83 \%$ had program content related to funding/grants, $83 \%$ had content related to curriculum/teaching, and $67 \%$ had content related to networking and collaboration (Table 4). For both scholarly activity and promotion/retention outcomes, the relative distribution of content found for successful programs was similar between programs for which goals and outcomes were aligned as well as those programs for which alignment of program goals and outcomes assessed was not considered (Tables 3 and 4).

\section{DISCUSSION}

This study analyzed program content areas, meeting frequency, program duration and evaluation period commonly associated with success among 34 faculty mentoring programs. This evaluation examined programs demonstrating successful scholarship and promotion/retention outcomes and characteristics that were consistently associated with faculty success. The data could be used to inform future program development at other institutions.

A critical step in developing a faculty mentoring program should be to identify desired goal(s) of the program. Setting clear goals from the onset can help identify administrative support needed ${ }^{55}$ and can be used to drive decisions regarding program content and outcome measurement indicative of success. Common programmatic goals for the programs assessed herein were improvement of scholarly activity (increased grant funding, publications), promotion and/or tenure, faculty retention rates, and faculty self-confidence and self-efficacy.

The structure and design of the mentoring model are important to the success of the program. This next step of designing and developing the program builds upon the purpose and goals already identified. ${ }^{55}$ Common structures within the programs reviewed include the dyad (mentor-mentee match) mentoring, peer mentoring, or a 
American Journal of Pharmaceutical Education 2019; 83 (1) Article 6976.

mixed model of both dyad and peer mentoring. Each model type has its own benefits and limitations. The dyad model, in which the mentee is typically paired with a more senior faculty member, is the traditional mentoring model and was the most commonly employed model among the programs analyzed in this study. For well-functioning mentor-mentee pairs, this model can result in considerable achievements by the mentee. However, success is highly dependent on this single relationship and, as such, when the mentor-mentee match is not optimal, the mentee's professional success may suffer. ${ }^{10,55}$ Additionally, the dyad model places the mentor at the center of the mentee's development and presumes that the mentor has knowledge and expertise regarding all things that the mentee would need, which may not be fair. Mentors are placed in positions in which they are pivotal for mentee success, but often without any training on how to be an effective mentor. Within the programs that were examined, the most commonly cited areas for improvement were incongruence in the mentor-mentee matches and a need for expanded mentor development and training.

The peer mentoring model eliminates the need for one mentor to serve at the center of the mentoring and avoids the hierarchical structure of the traditional dyad. Peer mentoring among faculty with mutual interests and similar rank may result in the development of supportive, reciprocal networks, collaboration, information sharing and strategic career planning. ${ }^{55}$ Peer communities facilitate the development of relationships characterized by mutual interests and shared power, facilitate connections that address psychosocial and emotional needs, and contribute to collegiality. ${ }^{8,55}$ Compared to the dyad model, far fewer programs used a model that was built solely around peer mentoring, and yet, several of these programs also reported successful outcomes. Within the studies examined, it was reported that peer mentoring enhanced collegiality, provided opportunities for the mentees to learn from each other, enhanced peer networking and promoted a sense of belonging and social support, which is consistent with prior studies. ${ }^{8,56}$ Programs reported that research collaborations developed from within the peer mentoring groups. However, peer mentoring participants noted some challenges with this structure, such as the risk that sessions would overemphasize personal matters and that the lack of a clear hierarchy (someone in charge) could be a source of tension, resulting in poorly structured meetings. An additional "twist" on the peer mentoring model is a facilitated peer mentoring system, in which a senior faculty member supervises and meets with the peer groups. This facilitated peer mentoring model can extend the reach of senior mentors whose availability may be limited and provides structure and the benefit of seasoned 


\section{American Journal of Pharmaceutical Education 2019; 83 (1) Article 6976.}

advice to the mentee that may not be available with a peeronly group. ${ }^{56,57}$

Similarly, several programs used a combination of both dyad and peer mentoring components. This dual approach can potentially mitigate many of the challenges experienced with either design alone. The mentees benefit both from the mentor pairing and the group interactions. Some programs instituted even more layers. Byington and colleagues used a "matrix model" that consisted of five mentoring levels: senior, scientific, staff, peer and selfmentoring. This model most closely resembles the conceptual framework of developmental networks, whereby mentoring occurs through multiple diverse relationships. ${ }^{10,58}$ These mentoring relationships include varying hierarchies and serve several different functions for the mentee and is not tied to an interpersonal relationship with a single person. ${ }^{10,55,58}$ In fact, within the programs analyzed, overall success rates were highest for mixed mentoring programs (eg, dyad plus peer mentoring or matrix model), followed by programs containing dyad-only structure, and then peer mentoring programs. However, within the programs examined, there were only three with the mixed mentoring. Therefore care must be taken not to over-interpret the estimation of success as compared to the other models.

After program goals and structure are defined, content areas within the mentoring program can be considered. For the programs assessed in this paper, program goals were categorized into one of three categories: professional development, research and scholarly activity, and promotion/retention. The most common content areas for all programs, regardless of stated goals, were research, funding/grantsmanship and networking/collaboration. These content areas were more commonly associated with programs reporting successful outcomes than with those programs for which success could not be determined.

Curriculum and teaching was commonly found in successful programs with the goal of promotion/retention. Although it is likely that all health sciences faculty could benefit from additional training in curriculum/teaching, inclusion of this content within programs with a goal of enhancing promotion/retention appears to be more important than if the mentoring program goals are related only to research and scholarly activity outcomes.

Another aspect to the design of programs that was not reflected in the categorization of the model designs was the inclusion of regular meetings/workshops in which programmatic content was formally delivered. Programs using mentoring plus a formal curriculum had higher rates of success compared to those programs that did not use a formal curriculum. Additionally, some of the successes of the formal curriculum may also have been related to meeting frequency. Often the formal curriculum was delivered once per month. It was observed that programs that met at least monthly, regardless of whether there was a formal curriculum, were commonly associated with success. Having structured, frequent meetings has also been identified as being important to mentoring success, with some authors suggesting that the frequency should be as common as weekly. ${ }^{5,59}$ Even though frequent meetings were found to be a key element to success, difficulty in finding time to meet, especially when meeting times and dates were left up to the participants, was often highlighted as a challenge. To entice the high frequency of participation necessary to facilitate this frequent contact, incentivizing mentors in some way may be something to consider. However, only 14 of the programs reviewed described giving the mentors incentives for their time and the incentives varied widely -- from meal allowance to salary offset.

Other structural considerations for program development include both the length of the mentoring program and the length of the follow-up period. How long faculty members need to be formally mentored in order to experience success in the goal areas should be considered. In the programs that were reviewed, the median duration of programs was 12 and 24 months, respectively, for those assessing promotion/retention and those measuring scholarly outcomes. Another area to consider is how long after the formal program ends should outcomes data be collected in order to determine if the program was successful. The median follow-up assessment periods were 33 and 84 months for programs assessing scholarly activity and promotion/retention, respectively. The length of the assessment period may influence the ability to capture positive outcomes. For example, many faculty may not be eligible for promotion for several years and therefore a prolonged assessment period of several years is likely necessary to assess true promotion-related outcomes. For the programs that were evaluated, we are unable to speculate as to whether a more prolonged assessment period would have converted some of the programs for which promotion/retention success could not be determined, into successful programs. However, when long evaluation periods are not feasible, shorter-term outcome measures such as performance evaluations may serve as valuable surrogate markers of long-term success.

Program evaluation is also a critical component of faculty development programs. Institutional time and resources are invested in the development and implementation of faculty mentoring programs. In the most basic terms, the institution needs to know if this investment was successful. A well-executed program evaluation is fundamental to understanding if the program is achieving 


\section{American Journal of Pharmaceutical Education 2019; 83 (1) Article 6976.}

its goals. Therefore, well-planned measurement is paramount. ${ }^{52}$ Using qualitative data, such as strength and weakness assessments and program perception, are especially useful during the formative stages of program development and could also be used on a continuous basis. However, these data should also be paired with summative evaluations, including both quantitative and qualitative measures appropriate for each program goal, to assess how effectively goals are being met for each individual participant as well as overall. ${ }^{55}$ For example, for programs with a goal of research/scholarship, quantification of numbers of publications and grants awarded are among the necessary information for assessing the program's impact and success. Additionally, the assessment strategy should be decided on during the planning stages of the mentoring program. The determination of success will require comparison to either the baseline (pre-program) data or comparison to a control group; either option needs to be included in the initial planning stages. Of the 34 individual programs included in this analysis, only about half (56\% of programs assessing scholarly outcomes and $54 \%$ of those assessing promotion/retention outcomes) reported data with respect to a comparison group, limiting our ability to determine success (or not) in the other groups and resulting in smaller sample sizes for analysis.

Of the studies for which success in one or more domains was determined, program components associated with success within mentoring programs were identified. This review is limited, however, in its ability to identify components or structural aspects of programs that could serve as discriminators between success or not in a mentoring program. Several factors contribute to this, including lack of or insufficient outcome reporting. A limitation of mentoring articles that has been reported previously, ${ }^{56}$ and was also true of the articles reviewed here, was that reported results were mainly descriptive, subjective, and were assessed via the use of locally developed and unvalidated surveys, and with metrics that lack standardization. There was also lack of consistency in reporting detailed information regarding specific course content that was covered within each program component (such as specifically stating topics of workshops). These factors, when taken together, made it difficult to draw conclusions regarding individual topic-level program components. Additionally, as mentioned above, some programs reported outcomes, but because of no baseline or comparator data, it was difficult to determine "success." Other studies did not report any outcomes or did not report on outcomes that were related to the programs' stated goals. Not reporting on these outcomes could have been a simple oversight or could be reflective of reporting or publication bias. Having so few programs that were unsuccessful decreases the ability to more fully understand the program components and content areas that would distinguish a successful versus unsuccessful program. It should also be noted that true measures of faculty "success" for an individual faculty member and/or for the institution for which they work, likely involves more than what was captured within the categorization of scholarly activity, promotion/retention, and confidence and self-efficacy.

\section{CONCLUSION}

The goal of this review was to identify specific programmatic components and structural features associated with success in order to inform others in the optimal design of mentoring programs within the health sciences. There are many key components associated with successful programs, including supplementing the mentoring component (whether it is a dyad, peer or mixed model) with a formal curriculum that has frequent points of contact (at least monthly meetings). Although somewhat dependent on the specific goals of the program, the curriculum should focus on scholarship, grantsmanship/ funding, curriculum and teaching, and networking/ collaboration. An additional important feature of a mentoring program is the inclusion of an appropriate assessment of program success, which is guided by program goals and includes either baseline or comparator data to more effectively determine success. With a greater number of strategically planned programs, future research can focus on identifying additional programmatic aspects critical in promoting faculty success.

\section{REFERENCES}

1. Monk PE, Irons JE, Carlson NL, Walker C. Mentoring: a safetynet for retention and tenure for faculty in institutions of higher education. Nat Soc Sci J. 2010;33(2):126-133.

2. Bucklin BA, Valley M, Welch C, Tran ZV, Lowenstein SR. Predictors of early faculty attrition at one academic medical center. BMC Med Educ. 2014;14(27):1-7.

3. Pololi LH, Krupat E, Civian JT, Ash AS, Brennan RT. Why are a quarter of faculty considering leaving academic medicine? A study of their perceptions of institutional culture and intentions to leave at 26 representative US medical schools. Acad Med. 2012;87(7):859-869. 4. Ambrose S, Huston T, Norman M. A qualitative method for assessing faculty satisfaction. Res High Educ. 2005;46(7):803-830. 5. Seely EW, Kram KE, Emans SJ. Developmental networks in translational science. Transl Res. 2015;165(4):531-536.

6. Jackson VA, Palepu A, Szalacha L, Caswell C, Carr PL, Inui T. "Having the right chemistry": a qualitative study of mentoring in academic medicine. Acad Med. 2003;78(3):328-334.

7. Straus SE, Sackett DL. What is the Evidence for Mentorship? In: Mentorship in Academic Medicine. Chichester, West Sussex, UK: John Wiley \& Sons; 2014:5-6.

8. Kram KE, Isabella LA. Mentoring alternatives: the role of peer relationships in career development. Acad Manag J. 1985;28(1):110132. 


\section{American Journal of Pharmaceutical Education 2019; 83 (1) Article 6976.}

9. Whitely W, Dougherty TW, Dreher GF. Relationship of mentoring and socioeconomic origin to managers' and professionals' early career progress. Acad Manag J. 1991;34(2):331-351.

10. Higgins MC, Kram KE. Reconceptualizing mentoring at work: a developmental network perspective. Acad Manag Rev. 2001;26(2): 264-288.

11. Allen TD, Eby LT, Poteet ML, Lentz E, Lima L. Career benefits associated with mentoring for protégés: a meta-analysis. $J \mathrm{Appl}$

Psychol. 2004;89(1):127-136.

12. Kram KE, Ragins BR. The landscape of mentoring in the 21st century. In: The Handbook of Mentoring at Work: Theory, Research, and Practice. Sage Publications Inc.; 2007:659-687.

13. Wutoh AK, Colebrook MN, Holladay JW, et al. Faculty mentoring programs at schools/colleges of pharmacy in the US. $J$ Pharm Teach. 2000;8(1):61.

14. Garman KA, Wingard DL, Reznik V. Faculty development: why bother? Development of junior faculty's self-efficacy: outcomes of a National Center of Leadership in Academic Medicine. Acad Med. 2001;76(10):S74-S76.

15. Wingard DL, Garman KA, Reznik V. Facilitating faculty success: outcomes and cost benefit of the UCSD National Center of Leadership in Academic Medicine. Acad Med. 2004;79(10 Suppl): S9-S11.

16. Ries A, Wingard D, Gamst A, Larsen C, Farrell E, Reznik V. Measuring faculty retention and success in academic medicine. Acad Med. 2012;87(8):1046-1051.

17. Ries A, Wingard D, Morgan C, Farrell E, Letter S, Reznik V.

Retention of junior faculty in academic medicine at the University of California, San Diego. Acad Med. 2009;84(1):37-41.

18. Thorndyke LE, Gusic ME, George JH, Quillen DA, Milner RJ. Empowering junior faculty: Penn State's faculty development and mentoring program. Acad Med. 2006;81(7):668-673.

19. Thorndyke LE, Gusic ME, Milner RJ. Functional mentoring: a practical approach with multilevel outcomes. J Contin Educ Health Prof. 2008;28(3):157-164.

20. Bean NM, Lucas L, Hyers LL. Mentoring in higher education should be the norm to assure success: lessons learned from the faculty mentoring program, West Chester University, 2008-2011. Mentor Tutor:Partnersh Learn. 2014;22(1):56-73.

21. Fox L. A personalized faculty peer support program: less can be more. J Fac Dev. 2012;26(2):55-61.

22. Haines SL, Popovich NG. Engaging external senior faculty members as faculty mentors. Am J Pharm Educ. 2014;78(5):Article 101. 23. Jackevicius CA, Le J, Nazer L, Hess K, Wang J, Law AV. A formal mentorship program for faculty development. Am J Pharm Educ. 2014;78(5):Article 100.

24. Law AV, Jackevicius C, Murray WI, et al. Impact of a faculty orientation and development committee. Am J Pharm Educ. 2012; 76(1): Article 3.

25. Kohn H. A mentoring program to help junior faculty members achieve scholarship success. Am J Pharm Educ. 2014;78(2):Article 29.

26. Benson CA, Morahan PS, Sachdev AK, Richman RC. Effective faculty preceptoring and mentoring during reorganization of an academic medical center. Med Teach. 2002;24(5):550-557.

27. Chen MM, Sandborg CI, Hudgins L, Sanford R, Bachrach LK. A multifaceted mentoring program for junior faculty in academic pediatrics. Teach Learn Med. 2016;28(3):320-328.

28. Files JA, Blair JE, Mayer AP, Ko MG. Facilitated peer mentorship: a pilot program for academic advancement of female medical faculty. J Women's Healh. 2008;17(6):1009-1015.
29. Daley SP, Broyles SL, Rivera LM, Brennan JJ, Lu ER, Reznik V. A conceptual model for faculty development in academic medicine: the underrepresented minority faculty experience. J Natl Med Assoc. 2011;103(9-10):816-821.

30. Phitayakorn R, Petrusa E, Hodin RA. Development and initial results of a mandatory department of surgery faculty mentoring pilot program. J Surg Res. 2016;205(1):234-237.

31. Pololi LH, Knight SM, Dennis K, Frankel RM. Helping medical school faculty realize their dreams: an innovative, collaborative mentoring program. Acad Med. 2002;77(5):377-384.

32. Kupfer DJ, Schatzberg AF, Dunn LO, Schneider AK, Moore TL, DeRosier M. Career development institute with enhanced mentoring: a revisit. Acad Psychiatry. 2016;40(3):424-428.

33. Morzinski JA, Simpson DE. Outcomes of a comprehensive faculty development program for local, full-time faculty. Fam Med. 2003;35(6):434-439.

34. Fox EC, Waldron JA, Bohnert P, Hishinuma ES, Nordquist CR. Mentoring new faculty in a department of psychiatry. Acad Psychiatry. 1998;22(2):98-106.

35. Morzinski JA, Diehr S, Bower DJ, Simpson DE. A descriptive, cross-sectional study of formal mentoring for faculty. Fam Med. 1996;28(6):434-438.

36. Lord JA, Mourtzanos E, McLaren K, Murray SB, Kimmel RJ, Cowley DS. A peer mentoring group for junior clinician educators: four years' experience. Acad Med. 2012;87(3):378-383.

37. Heinrich KT, Oberleitner MG. How a faculty group's peer mentoring of each other's scholarship can enhance retention and recruitment. J Prof Nurs. 2012;28(1):5-12.

38. Jacelon CS, Zucker DM, Staccarini JM, Henneman EA. Peer mentoring for tenure-track faculty. J Prof Nurs. 2003;19(6):335-338. 39. Mundt MH. An external mentor program: stimulus for faculty research development. J Prof Nurs. 2001;17(1):40-45.

40. Blauvelt MJ, Spath ML. Passing the torch: a faculty mentoring program at one school of nursing. Nurs Educ Perspect. 2008;29(1): 29-33.

41. Brown HN. Mentoring new faculty. Nurse Educ. 1999;24(1):4851.

42. Barksdale DJ, Woodley L, Page JB, Bernhardt J, Kowlowitz V, Oermann MH. Faculty development: doing more with less. J Contin Educ Nurs. 2011;42(12):536-537.

43. Bagramian RA, Taichman RS, McCauley L, Green TG, Inglehart MR. Mentoring of dental and dental hygiene faculty: a case study. $J$ Dent Educ. 2011;75(3):291-299.

44. Zeind CS, Zdanowicz M, MacDonald K, Parkhurst C, King C, Wizwer P. Developing a sustainable faculty mentoring program. Am J Pharm Educ. 2005;69(5):Article 100.

45. Tudiver F, Ferguson KR, Wilson JL, Kukulka G. Enhancing research in a family medicine program: one institution's story. Fam Med. 2008;40(7):492-499.

46. Law AV, Bottenberg MM, Brozick AH, et al. A checklist for the development of faculty mentorship programs. Am J Pharm Educ. 2014;78(5):Article 98.

47. Viets VL, Baca C, Verney SP, Venner K, Parker T, Wallerstein N. Reducing health disparities through a culturally centered mentorship program for minority faculty: the Southwest Addictions Research Group (SARG) experience. Acad Med. 2009;84(8):1118-1126.

48. Daley S, Wingard DL, Reznik V. Improving the retention of underrepresented minority faculty in academic medicine. J Natl Med Assoc. 2006;98(9):1435-1440.

49. Libby AM, Hosokawa PW, Fairclough DL, Prochazka AV, Jones PJ, Ginde AA. Grant success for early-career faculty in patient-oriented 


\section{American Journal of Pharmaceutical Education 2019; 83 (1) Article 6976.}

research: difference-in-differences evaluation of an interdisciplinary mentored research training program. Acad Med. 2016;91(12):

1666-1675.

50. Jordan C, Jones-Webb R, Cook N, Dubrow G, Mendenhall TJ, Doherty WJ. Competency-based faculty development in communityengaged scholarship: a diffusion of innovation approach. J High Educ Outreach Engagem. 2012;16(1):65-95.

51. Santucci AK, Lingler JH, Schmidt KL, Nolan BAD, Thatcher DL, Polk DE. Peer-mentored research development meeting: a model for successful peer mentoring among junior level researchers. Acad Psychiatry. 2008;32(6):493-497.

52. Franko DL. From nothing to something: the nuts and bolts of building a mentoring program in a health sciences college. Mentor Tutoring Partnersh Learn. 2016;24(2):109-123.

53. Byington CL, Keenan H, Phillips JD, et al. A matrix mentoring model that effectively supports clinical and translational scientists and increases inclusion in biomedical research: lessons from the University of Utah. Acad Med. 2016;91(4):497-502.
54. Baker JW, Bean J, Benge C, McFarland MS. Designing a resident research program. Am J Health Syst Pharm. 2014;71(7):592598.

55. Lumpkin A. A model for mentoring university faculty. Educ Forum. 2011;75(4):357-368.

56. Kashiwagi DT, Varkey P, Cook DA. Mentoring programs for physicians in academic medicine: a systematic review. Acad Med. 2013;88(7):1029-1037.

57. Landsberger SA, Scott EL, Hulvershorn LA, Chapleau KM, Diaz DR, McDougle CJ. Mentorship of clinical-track junior faculty: impact of a facilitated peer-mentoring program to promote scholarly productivity. Acad Psychiatry. 2013;37(4):288-289.

58. Beane-Katner L. Anchoring a mentoring network in a new faculty development program. Mentor Tutoring Partnersh Learn. 2014;22(2):91-103.

59. Boyle P, Boice R. Systematic mentoring for new faculty teachers and graduate teaching assistants. Innov Higher Educ. 1998;22(3): 157-179. 


\section{American Journal of Pharmaceutical Education 2019; 83 (1) Article 6976.}

Appendix 1. Individual Program Reports of Participant Perception, Satisfaction, Program Strengths, and Areas of Improvement

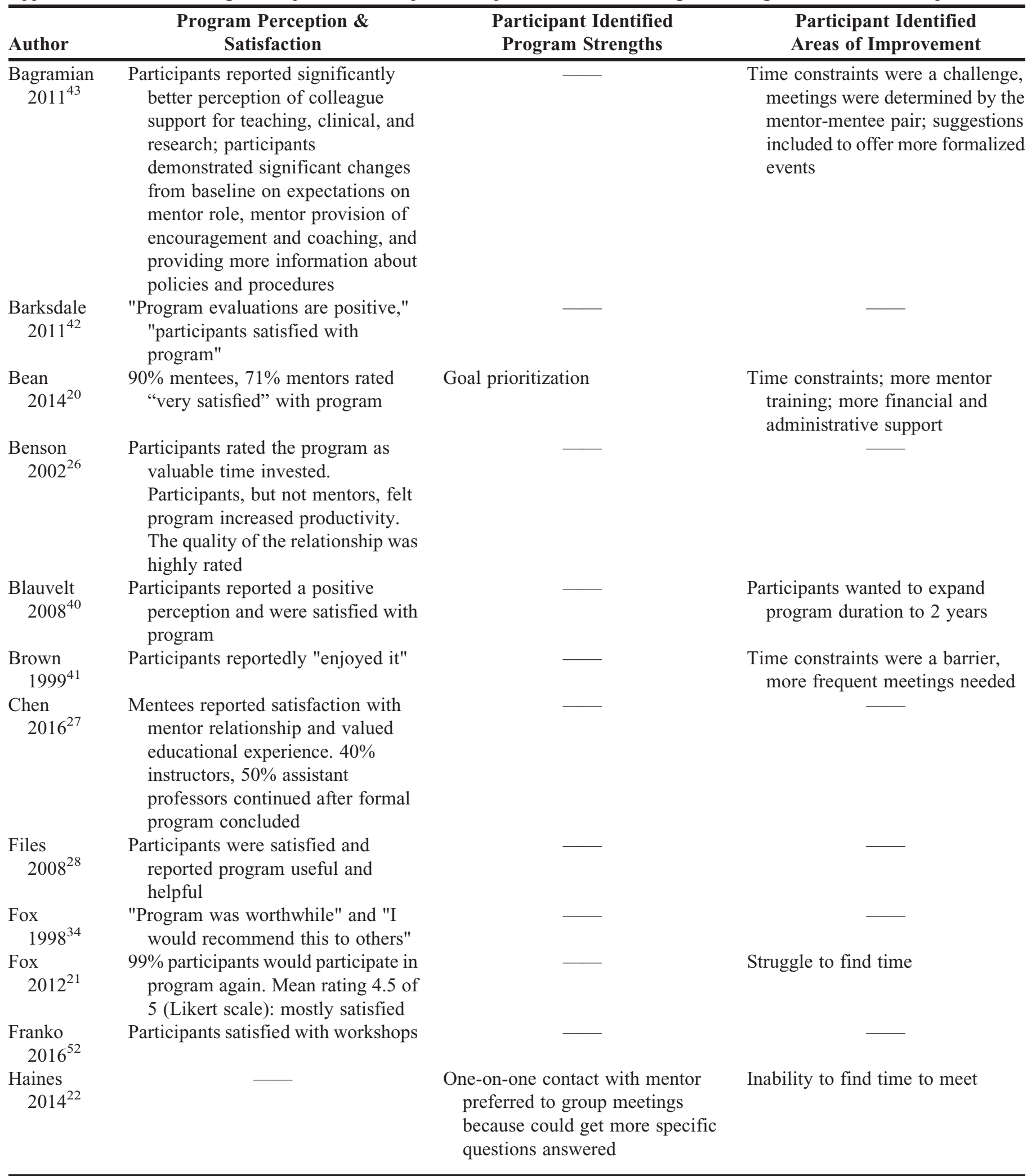


American Journal of Pharmaceutical Education 2019; 83 (1) Article 6976.

Appendix 1. (Continued)

\begin{tabular}{|c|c|c|c|}
\hline Author & $\begin{array}{c}\text { Program Perception } \& \\
\text { Satisfaction }\end{array}$ & $\begin{array}{l}\text { Participant Identified } \\
\text { Program Strengths }\end{array}$ & $\begin{array}{l}\text { Participant Identified } \\
\text { Areas of Improvement }\end{array}$ \\
\hline $\begin{array}{c}\text { Jackevicius } \\
2014^{23}\end{array}$ & $\begin{array}{l}\text { Majority of mentors }(83 \%-97 \%) \\
\text { satisfied with mentorship program } \\
\text { and its procedures. Majority of } \\
\text { mentees }(70 \%) \text { satisfied with } \\
\text { mentorship program, relationship } \\
\text { and logistics }\end{array}$ & - & $\begin{array}{l}\text { Meet more often, more initiative } \\
\text { and motivation, need for guidance } \\
\text { and specific activities }\end{array}$ \\
\hline $\begin{array}{l}\text { Kupfer } \\
\qquad 2016^{32}\end{array}$ & $\begin{array}{l}\text { Most faculty (14 of } 16 \text { participants) } \\
\text { were satisfied }\end{array}$ & - & $\begin{array}{l}\text { More time for peer mentoring } \\
\text { needed }\end{array}$ \\
\hline $\begin{array}{l}\text { Law } \\
\qquad 2012^{24}\end{array}$ & $\begin{array}{l}\text { Faculty noted: orientation helped to } \\
\text { ease into work at the university, to } \\
\text { understand expectations and to } \\
\text { feel welcome. Faculty were highly } \\
\text { satisfied (rating of } 4.4 \text { of 5). } 90 \% \\
\text { of faculty reported that workshops } \\
\text { helped improve teaching skills }\end{array}$ & - & $\longrightarrow$ \\
\hline $\begin{array}{c}\text { Morzinski } \\
1996^{35}\end{array}$ & 工 & $\begin{array}{l}50 \% \text { reported enriched relationship } \\
\text { with academic environment and } \\
56 \% \text { gained stronger beliefs in } \\
\text { importance of having a mentor }\end{array}$ & $\begin{array}{l}\text { Pairs that were closer in geographic } \\
\text { proximity or had well- } \\
\text { coordinated site visits reported } \\
\text { more positive impact of the } \\
\text { program }\end{array}$ \\
\hline $\begin{array}{c}\text { Morzinski } \\
2003^{33}\end{array}$ & $\begin{array}{l}\text { Satisfaction with content } 5.7-6.1 \text { ( } 7 \text { is } \\
\text { highest: very satisfied), with } \\
\text { presenter } 6.1-6.2 \text {, felt information } \\
\text { useful for knowledge acquisition } \\
5.6-6.1\end{array}$ & & - \\
\hline $\begin{array}{l}\text { Mundt } \\
2001^{39}\end{array}$ & $\begin{array}{l}\text { Participants felt supported and less } \\
\text { vulnerable }\end{array}$ & & 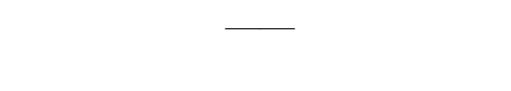 \\
\hline $\begin{array}{l}\text { Phitayakorn } \\
2016^{30}\end{array}$ & $\begin{array}{l}75 \% \text { of junior faculty very/somewhat } \\
\text { satisfied with program, however, } \\
17 \% \text { of mentees did not find work- } \\
\text { life benefit }\end{array}$ & 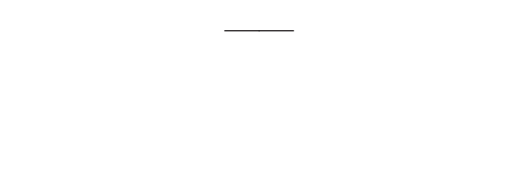 & $\begin{array}{l}\text { Improvement in matching process } \\
\text { needed }\end{array}$ \\
\hline
\end{tabular}


American Journal of Pharmaceutical Education 2019; 83 (1) Article 6976.

Appendix 1. (Continued)

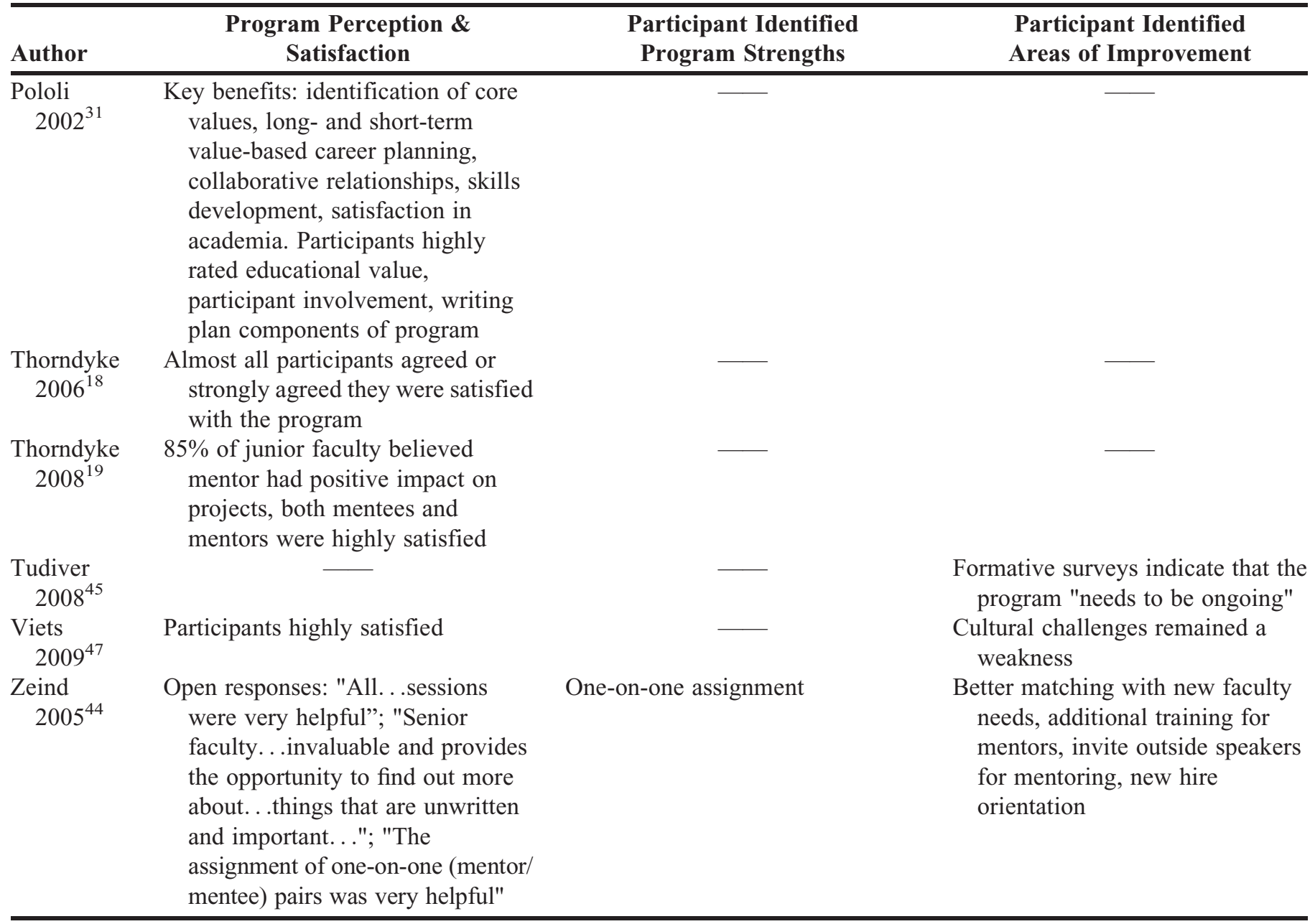

\footnotetext{
- No information provided
} 
American Journal of Pharmaceutical Education 2019; 83 (1) Article 6976.

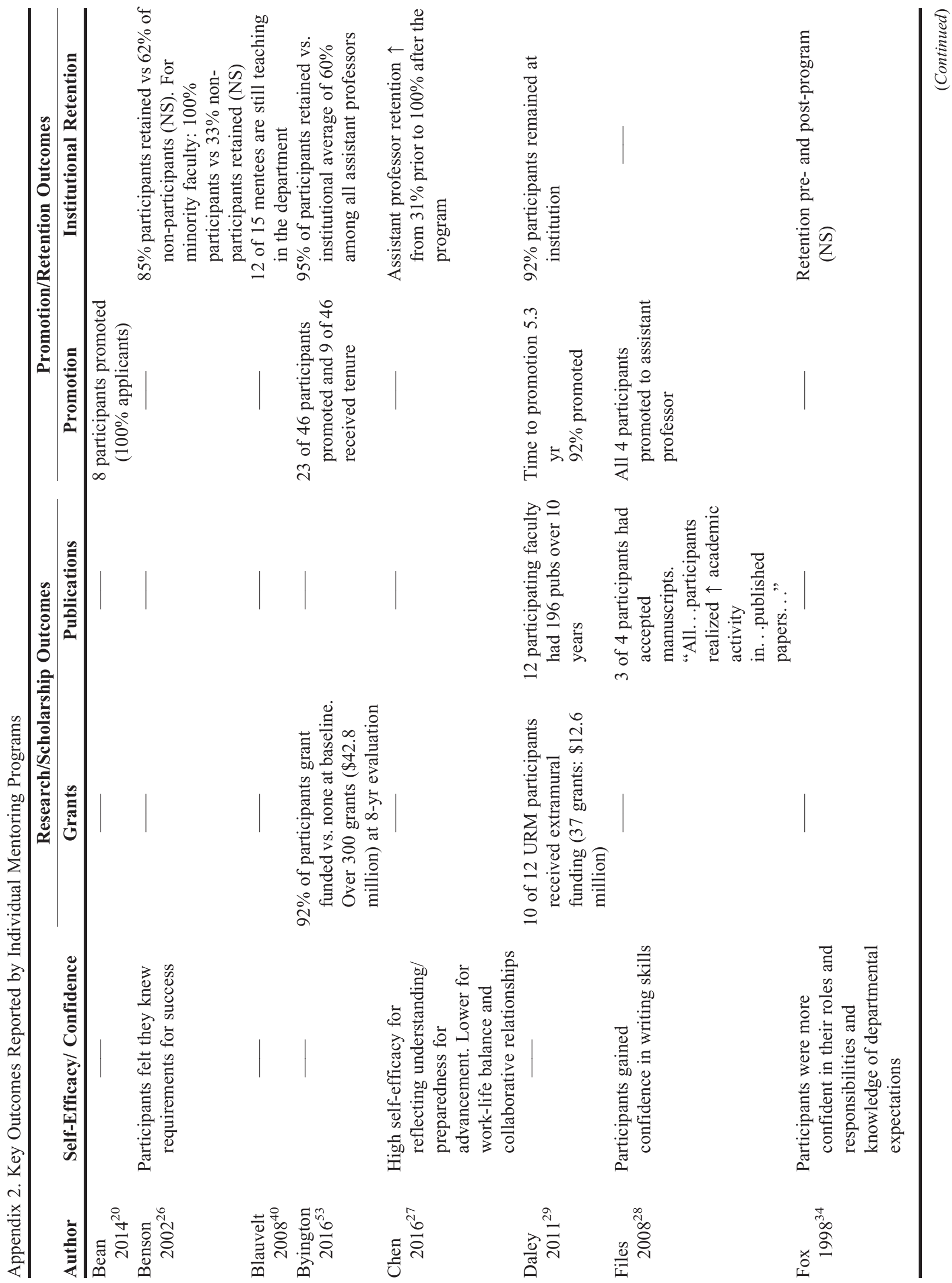


American Journal of Pharmaceutical Education 2019; 83 (1) Article 6976.

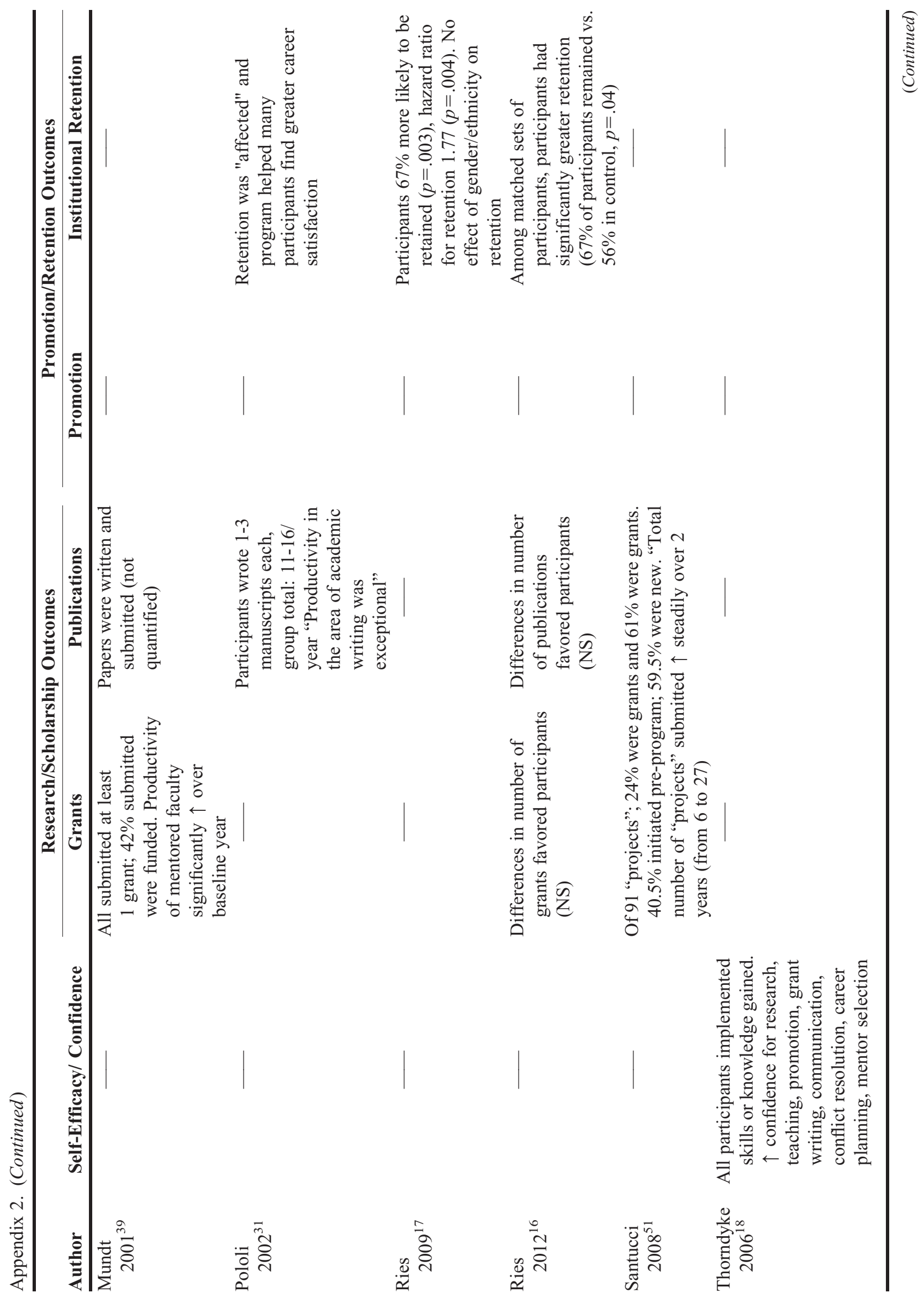


American Journal of Pharmaceutical Education 2019; 83 (1) Article 6976.

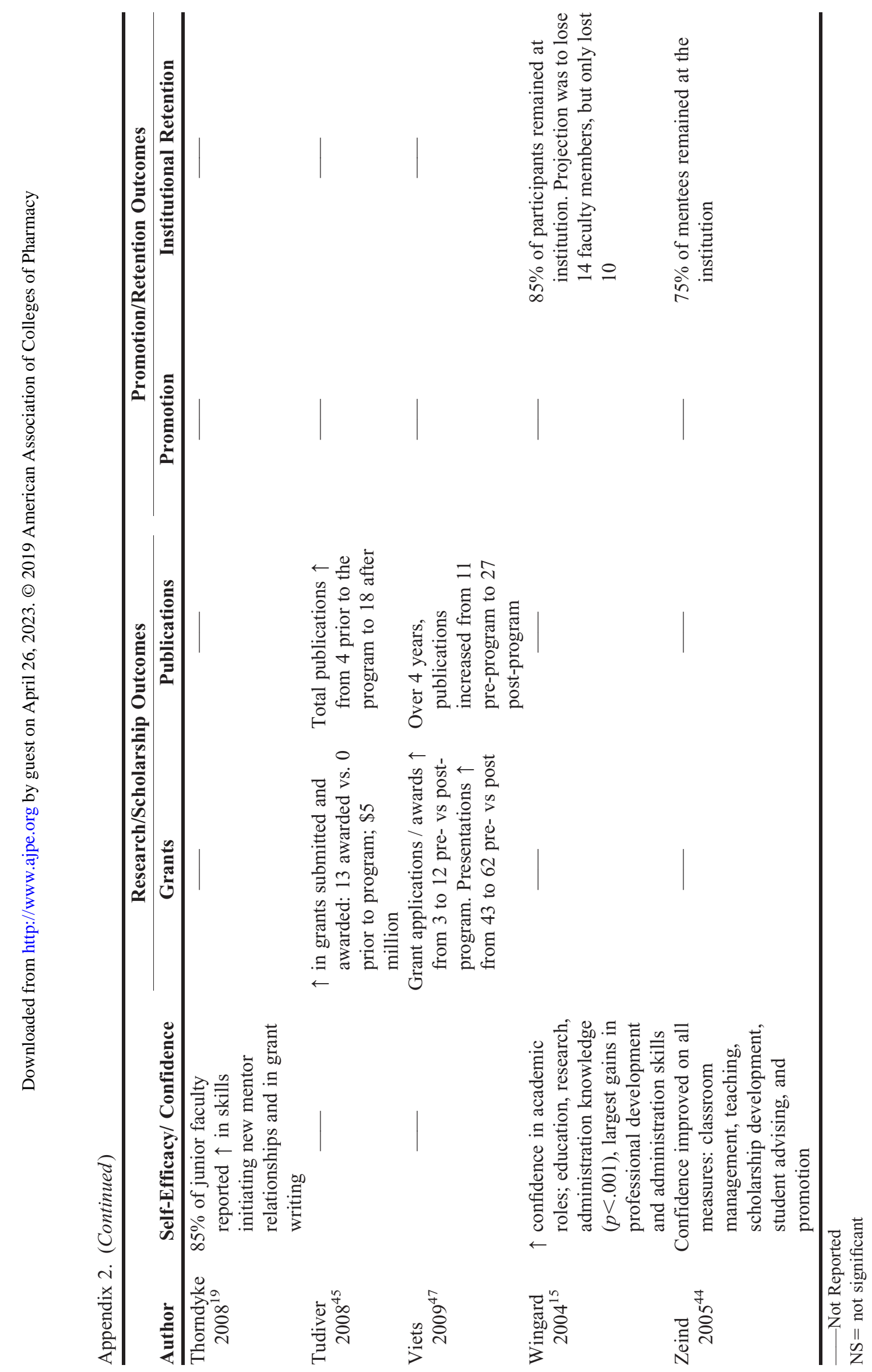

